\title{
Synergistic activity of azithromycin combined with metronidazole against toxoplasmosis in experimental mice
}

\author{
Ziad H.Al-jader, Abdulsalam M. Al-Mukhtar \\ Department of Microbiology, Mosul College of Medicine, \\ University of Mosul, Iraq

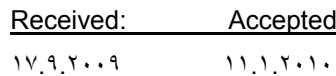

\begin{abstract}
Objective: To evaluate the efficacy of synergistic activity of azithromycin combined with metronidazole against toxoplasmosis experimentally induced in murine model.

Material \& Methods: Albino mice model (balb/c mice) acutly infected with tachyzoites, were treated for $1 \cdot$ days from day +1 postinfection with administration of azithromycin combined with metronidazol.
\end{abstract}

Results: The results showed that prolonged survival of albino mice relative to that of untreated control, and the dead mice were found only in the control group. This experiment showed that a remarkable synergistic effect on toxoplasmosis was obsereved when azithromycin was adminstratered in combination with metronidazole at cuurative dosage i.e.( $r_{\circ} \cdot$ and $r_{.} \cdot \mathrm{mg} / \mathrm{kg} /$ day), respectively. These results showed that azithromycin, which is remarkably active on toxoplasmosis, significantly potentiates the curative effect of metronidazol in the treatment. The treated mice in uncontrolled group were completely cured from toxoplasmosis as their brain were free of $\mathrm{T}$. gondii cyst either microscopically or by bioassay.

Conclusion: Combined drugs of azithromycin and metronidazole showed a cure rate of $1 . . \%$ in experimental murine toxoplasmosis.

الخلاصة

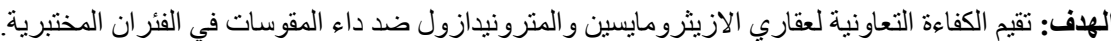

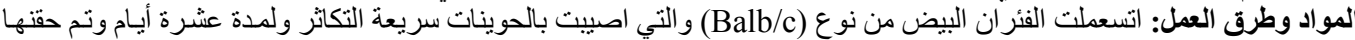

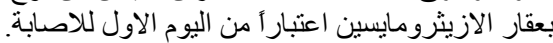

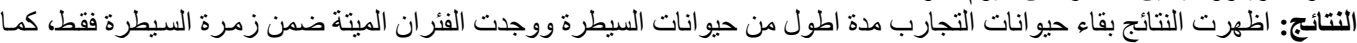

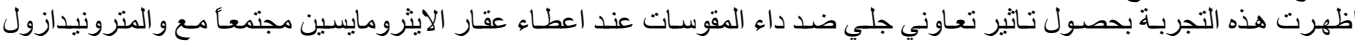

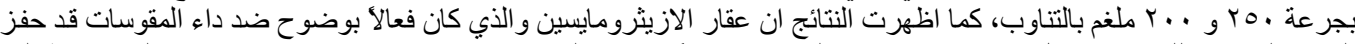

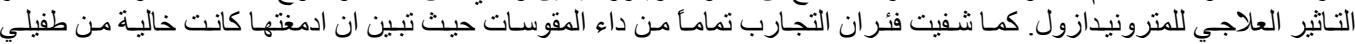

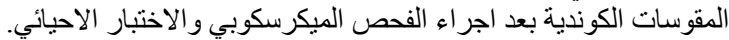

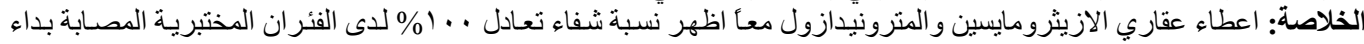

$\mathrm{T}$ ondigi is the one of the most common protozoan of mammals, birds and considered as an important human pathogens which is typically a brain infection and can also affect the eye and other organs. Only the cats play a major role in transmission of the disease because they harbor the reproductive forms of the parasite.' Usualy the acute infection with T.gndii is either asymptomatic or cause mild symptom,' but in case of transmission of this parasite to the fetus during pregnancy, the development of a congenital infection that can result in a fetopathy, but the disease in the fetus is usually more severe earlier in pregnancy that infection and transmission occurs $^{r}$ The most severe form of toxoplasmosis occur in immunocompromised patients includeing AIDS, malignancis, leukemia,collagen vascular diseases, organ transplant recipients and infected new born patients with ocular toxoplasmosis and women who are infected during gestation.

Treatment of toxoplasmosis has not changed essentially during the past few decades, consist of various combination of 
antibiotic drugs; the most common agents used are pyrimethamine, clindamycin, and the sulphonamides. These drugs are some times given in combination with corticosteroids to alleviate the inflammatory reaction especially in treatment of ocular toxoplasmosis which is responsible for the tragic loss of eye sight in this parasitic disease. In addition, the combination of these drugs in the standard therapy regimen has been successful in most patients but may cause bone marrow suppression, hematological toxicity and or life threatening allergic reactions." The relatively results in a lowering of the dosage or discontinuation of one or both drugs in the combination therapy predisposing to failure of treatment. ${ }^{\gamma}$ Thus the purpose of this study is to investigate alternative drugs with lower level of toxicity and increase potencies to treat toxoplasmosis. As far as we know the present was the first to evaluate the efficacy of the combination of azithromycin and metronidazole in the treatment of experimental toxoplasmosis.

\section{Material and Methods \\ Collection of samples}

T.gondii was originally isolated from sixty suspected infected placentae taken from aborted and sixty normal delivery women attending $\mathrm{Al}$-Batol, $\mathrm{Al}-\mathrm{Khansah}$ and $\mathrm{Al}-$ Salam Teaching Hospitals in Mosul. All samples of placentae were examined microscopically by direct methods, and biopsy was done in normal (uninfected) mice to confirm the diagnosis. ${ }^{\wedge}$ The infected one processed according to the method described by previous workers. From each placenta $0 . \mathrm{g}$ were taken and cut into small pieces mixed with equal volume of normal saline and grinded with mortar and a pestle or homogenized by electric homogenizer. The suspension was filtered through cotton to avoid large particles .

One thousand units of penicillin and 1.. mg of streptomycin were added to prevent contamination.' 1.' $\mathrm{ml}$ of the filtered solution inoculated through intraperitoneal passage in laboratory bred, healthy Swiss albino mice ( $\left.\wedge_{-}\right)$. weeks old) to maintain the infection of intraperitonial fluid with T.gondii. These infected mice were sacrificed within r-s days after inoculation. They were regularly inoculated intraperitonealy throughout the experiment by means of sterile tuberculine syringe, delivering $\cdot . \cdot \cdot r \mathrm{ml}$ of fresh peritoneal exudate taken from a mouse inoculated intraperitonealy $r$ days before. ' The exudates contained approximately 0 . organisms $/ / \mathrm{ml}$. Dilution of heavily infected exudate was done with sterile normal saline solution. 'T The experimental white albino mice (Balb/c strain) $\left.\Lambda_{-}\right)$. weeks old of both sexes were used, and these mice were examined to be sure that they were not infected with toxoplasmosis by using serological tests Latex agglutination \& ELISA.'

Induction of toxoplasmosis in mice: For evaluation to get infection orally or intraperitonally equal doses of tissue cysts ( $\mathrm{ml}$.) contain $\bullet$. cysts were given to $r$. mice. These mice were divided into two groups. The first group of mice were given orally, and in the second group, cysts were given by inoculation intraperitonally. The peritoneum exudates were examined for each group $r_{-} \tau$ days after inoculation for diagnosis of $T$. gondii. One month after inoculation the mice were sacrificed, their brains were examined to find the tissue cysts. The inoculation was also done in another $r$. mice by using equal doses ( $\mathrm{ml}$ ) contain $\odot$. tachyzoites inoculated orally and intraperitonally. The mice were under observation for diagnosis of the parasite as mentioned before.

Combined antimicrobial chemotherapy: 1.Azithromycin. This drug is an antibiotic belongs to the macrolide group, Its action is to bind to the $0 . \mathrm{S}$ subunit of bacterial ribosomes, blocking protein synthesis,

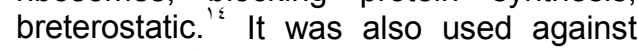
parasitic infection like cryptosporidiosis and angiomatosis, also has potent activity against chronic experimental toxoplasmosis.

r. Metronidazole. (benzoyl metronidazol) It has fungicidal activity and also it has a direct action on parasitic infection like trichmoniasis, giardiasis cryptosporidiosis and amoebiasis. It is thought to enter the cells of microorganisms that contain nitroreductase. Unstable compounds are then formed that bind to DNA and inhibit its synthesis, causing cell death.'

The doses of combined drugs used in this experiment were as follows:

Azithromycin ( $\left.\mathrm{O}^{\circ} \cdot \mathrm{mg} / \mathrm{kg}\right)+$ Metronidazole $(r \cdots m g)$. Ten infected mice by intraperitoneal cysts were treated with metronidazole and azithromycin which was given before. The combined treatment was given $r \leqslant$ hours after inoculation and continued for $1 \leqslant$ days post-infection. The 
mice were under observation for $r$. days, and the experiment was terminated after so days post-infection.Other ' - mice was not given anytreatmentand served as control. At the end of the experiment all mice were sacrificed. Microscopical examination and bioassay were done for brain of mice, and the living mice were evaluated for efficacy of drugs used. Data were analyzed statistically using Ztest between two proportions to compare between methods and drugs. The results were considered significant at $(P<\cdot . \cdot 0)$. Numbers, percentages were also calculated.

\section{Results}

Synergistic activity of azithromycin and metronidazole

All ten mice were found dead in the control group. These mice had not been given any treatment from the $v$ th day till the l sth day after inoculation with $T$. gondii. They showed signs and symptoms of illness (weakness, piloerction, ascitis of abdomen) which were not seen in treated group. After three days from the beginning of treatment the mice became active and their activity were normal in the period of treatment ( $1 \leqslant$ days) then the treatment was stopped for all mice. The observation of these mice was continued for the period of $r$. days. The results revealed that the dead mice were found only in controlled group, but those mice which treated with azithromycin plus metronidazole were still living. This experiments showed that the synergistic activity of azithromycin and metronidazole had the ability to protect mice from acute toxoplasmosis, and there was a significant difference $(P<\cdot . \cdot)$ in the treated group in comparison with the control group (Table 1).

\section{Discussion}

Metronidazole is an antibiotic approved as a fungicidal ,and act against $T$. vaginalis, E.histolytica and works at both intestinal and extraintestinal amoebiasis, and this antiprotozoal drug enter into the microorganisms and bind to DNA and inhibited synthesis leading to cell death ${ }^{\text {'r }}$, azithromycin, a similar drug, have been approved as antitoxoplasmosis, and nontoxic, and azithromycin cannot prevent recurrent disease ${ }^{\wedge}$, so they might be useful in treating toxoplasmosis, and to bring attention to these treatment possibilities, so that others can investigate further and organize clinical trails to determine whether these drugs are valuable for treatment of toxoplasmosis and the possibility of preventing recurrence of ocular toxoplasmosis and for treating AIDS-related infections.

The results showed that all 1. mice in the control group died due to ascites. The parasites were detected in the peritoneal cavity and in the brain of dead mice. The result showed that all mice were alive in group which had been treated with azithromycin combined with metronidazole (Table 1). Others they showed that the combination of azithromycine with pyrimethamine resulted in a greater inhibition of Toxoplasma protein synthesis compared to azithromycin alone in vitro assay using mouse macrophages challenged with $T$. gondii tachyzoites ${ }^{19}$ thus,our results showed that using azithromycin and metronidazole in experimental infection in mice with $T$. gondii is considered as fruitful work which gave a good result in the treatment. This study showed that the combined use of the drugs yielded better results in terms of cure rates. So these results indicates that evaluation of the efficacy of azithromycin and metronidazole, preferably by means of randomized studies is needed to determine the future role of these and other drugs in the treatment of toxoplasmosis and the possibility of preventing recurrence of ocular toxoplasmosis and for treating AIDSrelated infections. 
Table 1: Effect of combined antimicrobial agents in mice infected with T.gond

\begin{tabular}{|c|c|c|c|c|c|}
\hline \multirow[t]{3}{*}{ Group } & \multirow{3}{*}{$\begin{array}{l}\text { Antimicrobial dose } \\
\text { (mg/kg daily) }\end{array}$} & \multicolumn{4}{|c|}{$\leqslant 0$ days after infection } \\
\hline & & \multicolumn{2}{|c|}{ mice } & \multicolumn{2}{|c|}{ Bioassay for living mice } \\
\hline & & No. & Living \% & No. & Cure $\%$ \\
\hline First & $\begin{array}{l}\text { Azthromycin Y०. } \\
\text { +Metronidazole Y.. }\end{array}$ & 1. & $1 \ldots \%$ & 1. & $1 \ldots \%$ \\
\hline Second & Control no treatment & 1. & . & . & . \\
\hline
\end{tabular}

\section{References}

1. Striepen B, Grawford M, Shaw ML, et al. The plastid of Toxoplasma gondii divided by association with coutrosomes. Cell Biol $r . . ; 101: 1 \leqslant r r-1 \leqslant r \leqslant$.

Hliman RE. Congenital toxoplasmosis. Jor.Hosp. Infect $1990 ; r \cdot: 1 \mathrm{~V} \cdot-19 \cdot$.

r. Dubey JP, Advances in the life cycle of Toxoplasma gondii. Int Jor Parasitol 199^a; $r \wedge: 19-r \varepsilon$.

£. Dunay Ir, Heimeasaat MM, Bushrab Fn, Muller RH, Atovaquone. Maintenance of Toxoplasma Encephalitis in Murine Model of Reactivated Toxoplasmosis. Antimicrob Agents Chemother.

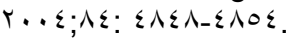

- Montoya JG, Liesenfeld O. Toxoplasmosis. Lancet. r... ; r rז: $1970-197 \mathrm{~V}$.

7. Holiman RE. Congenital Toxoplasmosis. Jor.Hosp. Infect. 1990; r.: $1 V_{\cdot--19 .}$

v. Dubey, J.P. and Beattie, C.P. Toxoplasmosis of animals and man. CRC Press, Baca Raton, Florida. 199^; 0: $\leqslant 0-\varepsilon \wedge$.

^. Remington JS, Thulliez $\mathrm{PH}$, Montoya, JG. Recent developments for diagnosis of toxoplasmosis $\mathrm{J}$. Clin. Microb. $r \ldots \varepsilon ; \leqslant r(r): 9 \leqslant 1-9 \leqslant 0$.

१. Manson-Bahr, P.E.C. and Bell, D.R. Manson's Tropical Diseases. 19th. ed. Bailler Tindall, Philadelphia. $19 \wedge v ; \leqslant \vee-\varepsilon \Lambda$.

1. Al-Hayalli ssm. Experimental study on isolates of Toxoplasma gondii from human placenta and the efficacy of some antibioyic in its treatment induced in

mice. Ph.D. thesis. University of Mosul,Iraq. r... r.

11. Ahmed JH, Safar EH, OmarSH, et al. Toxoplasma gondii antibodies in clinically suspected cases of toxoplasmosis. J. Egypt. Soc. Parasitol. 1994 rт(ए): 70r-709.

ir. Mcfadden DC., Cammps M. Bothrryd, J.C. Resistance as a toll in the study of old and new drug targets in toxoplasmosis,. Drug Resistance updates. r...; $\leqslant: \vee \vee-\Lambda \varepsilon$

1r. Jeffries, A.C. and Johnson, A.M. The growing importance of plaslid-like DNAs ofa picomplexa. Int. J. Parasitol. 1997; r7: $1149-110$.

1 ₹. Paniker CKJ. Text book of medical parasitology oth ed. Jaypee brothers. medical publishers LTD, New Delhi. r...r; 19.90.

10. Sabah Saeid Mahmoud. Azithromycin macrolids with a potent activity on chronic experimental toxoplasmosis.

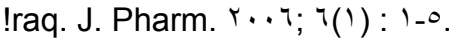

17. Blais J ; Beachamp, D. ; Chamberland, S. Azithromycin uptake and intracellular accumulation by Toxoplasma gondii Infected macrophages. Jor. Antimicrob. Chemother. $199 \leqslant ; r \varepsilon(r)$ : $r v 1-\lambda r$.

IV. Paniker CKJ Text book of medical parasitology oth ed. Jaypee brothers medical publishers LTD, New Delhi.r... r: ^9.9०.

1^. Aniki Rothova, Lotie E.H., ; BoschDeiessen, et al. Azithromycin for ocular toxoplasmosis. Br J Ophthalmol

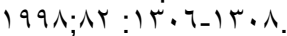

19. Blais J, Beachamp D, Chamberland S. (Azithromycin uptake and intracellular accumulation by Toxoplasma gondii Infected macrophages. J. Antimicrob. Chemother. $199 \leqslant ; r \leqslant(r): r v 1-\Lambda$. 